Revista Destaques Acadêmicos, Lajeado, v. 11, n. 3, 2019. ISSN 2176-3070

DOI: http://dx.doi.org/10.22410/issn.2176-3070.v11i3a2019.2229

http://www.univates.br/revistas

\title{
ANÁLISE DO USO DE PLANTAS MEDICINAIS E MEDICAMENTOS EM HABITANTES DO MUNICÍPIO DE CAPITÃO/RS
}

\author{
Luciara Sartori Riboldi ${ }^{1}$, Marinês Pérsigo Morais Rigo²
}

Resumo: O uso de plantas medicinais pela população é um hábito muito comum repassado de geração em geração entre as famílias desde à antiguidade, porém algumas plantas se usadas de forma incorreta podem causar interações medicamentosas, reações adversas e efeitos toxicológicos no organismo. Desta forma, o objetivo deste estudo foi analisar as interações entre plantas medicinais e medicamentos no município de Capitão/ RS. Para isso, foi aplicado um questionário sobre plantas medicinais e medicamentos, com perguntas objetivas e descritivas à usuários que frequentam o Posto de Saúde da cidade de Capitão. A pesquisa contou com 50 participantes de ambos os sexos, onde a predominância foi do sexo feminino, a idade média dos entrevistados foi entre 61 a 70 anos, sendo a maioria aposentados e com ensino fundamental incompleto. No geral, quase todos disseram utilizar plantas medicinais, que este hábito foi repassado pela família e que normalmente são cultivadas no quintal de casa. As plantas mais citadas foram camomila (Matricaria recutita), marcela (Achyrocline satureioides), capimlimão (Cymbopogon citratus), boldo (Plectranthus barbatus), funcho (Foeniculum vulgare), malva (Malva sylvestris), laranjeira (Citrus sinensis), poejo (Mentha pulegium) e losna (Artemisia absinthium). A forma de preparo mais utilizada foi a infusão e as partes mais usadas foram as folhas. Os medicamentos mais citados foram os que agem no sistema cardiovascular, seguido dos medicamentos que atuam no aparelho digestivo, betabloqueadores, antidepressivos, anti-hipertensivos e diuréticos. Em relação às interações encontradas, várias plantas medicinais podem provocar interações ou alterar a absorção dos fármacos, como a camomila (Matricaria recutita) que possui interação com anticoagulantes, fazendo com que aumentem as chances de hemorragias, assim como o capim-limão (Cymbopogon citratus) que interage com medicamentos sedativos, podendo aumentar seus efeitos. $O$ fato da população achar que o que é natural não faz mal, deve ser visto com maior atenção pelos profissionais da área de saúde em relação ao uso de medicamentos associados às plantas medicinais, visando garantir

1 Acadêmica do curso de Pós-Graduação em Farmácia Estética da Universidade do Vale do Taquari - Univates, Lajeado, RS, Brasil. luciara1910@gmail.com

2 Coordenadora do Curso de Farmácia Centro de Ciências Biológicas e da Saúde, da Universidade do Vale do Taquari - Univates, Lajeado, RS, Brasil. 
maior segurança, diminuindo as interações e contribuindo para uma melhor qualidade de vida.

Palavras-chave: Fitoterapia; Plantas medicinais; Medicamentos; Interações.

\section{INTRODUÇÃO}

Segundo a legislação sanitária brasileira, fitoterápicos são medicamentos provenientes de matérias-primas vegetais, que apresentam qualidade, segurança e eficácia comprovadas (VIEIRA; REDIGUIERI, 2013). O uso de plantas medicinais por diversas culturas como principal matéria-prima para a fabricação de medicamentos, prevenção e/ou a cura de doenças, é um hábito que sempre existiu na história da humanidade, e são consideradas até hoje as mais antigas "armas" empregadas pelo homem (MORAES; SANTANA, 2001) e (ODY, 1993). A Organização Mundial da Saúde (OMS) estima que cerca de $80 \%$ da população mundial faz o uso de plantas ou preparações da mesma para tratamento na atenção primária de saúde (BRASIL, 2006a).

O Brasil tem a maior biodiversidade do mundo, quase um terço da flora mundial, com um amplo patrimônio genético e uma grande diversidade cultural, sendo considerado um grande potencial para pesquisas a partir de matériasprimas vegetais. Marcos extremamente importantes foram firmados para estabelecer o uso racional de medicamentos contendo plantas medicinais, como a aprovação da Política Nacional de Práticas Integrativas e Complementares (PNPIC) no Sistema Único de Saúde (Portaria n. 971 de 03 de maio de 2006) e do Decreto $n^{\circ} .5813$, de 22 de junho de 2006 que aprova a Política Nacional de Plantas Medicinais e Fitoterápicos e dá outras providências (BRASIL, 2006b). Em 2008 foi publicada a Instrução Normativa no .5 , de 11 de dezembro de 2008 que traz a Lista de Medicamentos Fitoterápicos de Registro Simplificado, onde as espécies de plantas utilizadas para fins medicinais foram padronizadas com informações como nome popular, parte usada, padronização/marcador, derivados utilizados de droga vegetal, indicações/ações terapêuticas, dose diária, via de administração e restrição de uso (BRASIL, 2010).

O consumo de plantas medicinais com pouca ou nenhuma comprovação de suas propriedades farmacológicas é muito amplo no nosso país, tornando-se necessário estudos sobre finalidade, riscos e benefícios, pois a utilização de algumas plantas medicinais podem desencadear efeitos adversos indesejados decorrentes da falta de informação, seja pela incorreta identificação farmacobotânica, indicações terapêuticas sem comprovação científica e interações medicamentosas, a fim de garantir a segurança e eficácia aos usuários (JUNIOR et al., 2005).

Assim, o presente estudo descritivo transversal teve como objetivo descrever o uso de plantas medicinais associado ao uso de medicamentos por usuários do Serviço Público de Saúde do município de Capitão/RS. 


\section{METODOLOGIA}

Esta pesquisa é do tipo observacional de caráter quantitativo, realizada por meio de um questionário com perguntas objetivas e descritivas, aplicado aos usuários que buscam atendimento no Serviço Público de Saúde do município de Capitão/RS. Capitão é um município localizado no interior do Rio Grande do Sul, cuja área territorial corresponde a $70 \mathrm{Km}^{2}$ e uma população de 2.741 habitantes. O município possui colonização alemã e italiana e 93,48\% da economia é a agropecuária, onde é muito comum o hábito de consumir plantas medicinais.

Os dados foram coletados através de um questionário na forma de entrevista, com perguntas relacionadas às plantas e medicamentos utilizados pela população foco do estudo. A aplicação do questionário ocorreu no mês de janeiro de 2019 e foi constituída por 50 pessoas de ambos os sexos que frequentaram o Posto de Saúde neste período e aceitaram participar da pesquisa.

O questionário abrangia perguntas sobre medicamentos de uso contínuos, medicamentos de uso esporádicos, costumes ou crenças repassadas por outras gerações, conhecimento popular sobre plantas medicinais e suas indicações terapêuticas, além de outras variáveis como, sexo, idade, escolaridade e profissão.

Todas as informações obtidas após a aplicação do questionário foram comparadas com dados descritos na literatura, apesar da falta de conhecimento dos entrevistados na identificação das plantas e a ausência de informações científicas. $\mathrm{O}$ fato de não existirem estudos suficientes para todas plantas citadas na pesquisa, não descarta a hipótese de existirem possíveis interações entre plantas e medicamentos ainda não estudadas. Consequentemente, a falta de interações será descrita com a seguinte sigla: NE (não encontrados). Todas as informações foram tabuladas em planilha do programa Microsoft Excel ${ }^{\circledR} \mathrm{e}$ analisadas por estatística descritiva.

O projeto foi aprovado pelo Comitê de Ética em Pesquisa da Univates, seguindo todas as diretrizes da Resolução $\mathrm{n}^{\circ}$ 466, de 12 de dezembro de 2012, do Conselho Nacional de Saúde, sob o parecer n ${ }^{\circ}$ 2.823.015.

\section{RESULTADOS E DISCUSSÃO}

Foram realizadas 50 entrevistas entre homens e mulheres, sendo que $68 \%$ eram mulheres e apenas $32 \%$ eram homens. A predominância do sexo feminino presente neste levantamento, demonstra que as mesmas possuem maior conhecimento sobre as plantas e seu preparo, e também por serem responsáveis pelas tarefas do lar e terem maior disponibilidade para participarem da pesquisa. Essa predominância também foi observada nos estudos realizados por Vendrúscolo \& Mentz (2006), Szerwieski et al. (2017) e Maravai et al. (2011). 
Em relação à idade dos indivíduos, ocorreu uma variação de 20 a 90 anos, onde a predominância foi entre 61 a 70 anos, conforme o Gráfico I.

Gráfico I - Percentual de idade dos entrevistados distribuídos por faixas etárias

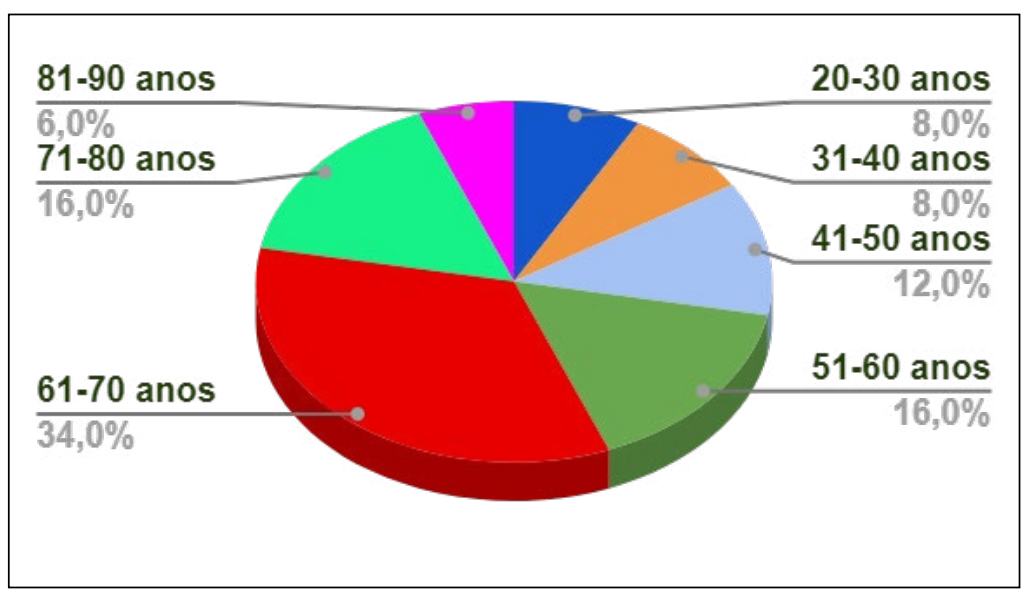

No que se refere à escolaridade, a maioria dos entrevistados possui ensino fundamental incompleto, correspondendo a $70 \%$. Quanto às profissões, houve predomínio de aposentados $(44 \%)$, os agricultores aparecem com $(16 \%)$ e as donas de casa representam (14\%).

Sobre o uso de plantas medicinais, $88 \%$ dos entrevistados relataram usar para o tratamento de algum tipo de enfermidade e $12 \%$ não utilizavam nenhum tipo de planta medicinal. O hábito de consumir plantas medicinais foi apontado como um conhecimento que é repassado de geração em geração pelas famílias, representando um total de $76 \%$. Sobre onde adquirem as plantas medicinais, $90 \%$ dos entrevistados informou adquirir no seu próprio quintal, enquanto que $16 \%$ declararam que adquirem com conhecidos e o restante em beiras de estrada, supermercados e farmácias.

Os medicamentos foram relacionados conforme a classificação ATC (Anatomical Therapeutic Chemical), onde foi possível verificar que do total dos entrevistados, $90 \%$ fazem uso de medicamentos contínuos e citaram 50 nomes de fármacos, sendo os mais consumidos são os que agem no sistema cardiovascular, em segundo lugar, os medicamentos que atuam no aparelho digestivo e metabolismo, seguidos de betabloqueadores, antidepressivos, anti-hipertensivos e diuréticos, como demonstra o Gráfico II. Já o uso de medicamentos esporádicos, representa $70 \%$ e as classes mais citadas foram os analgésicos e os anti-inflamatórios, usados para dores leves e moderadas. 
Gráfico II - Percentual de medicamentos de uso contínuo citados pela população

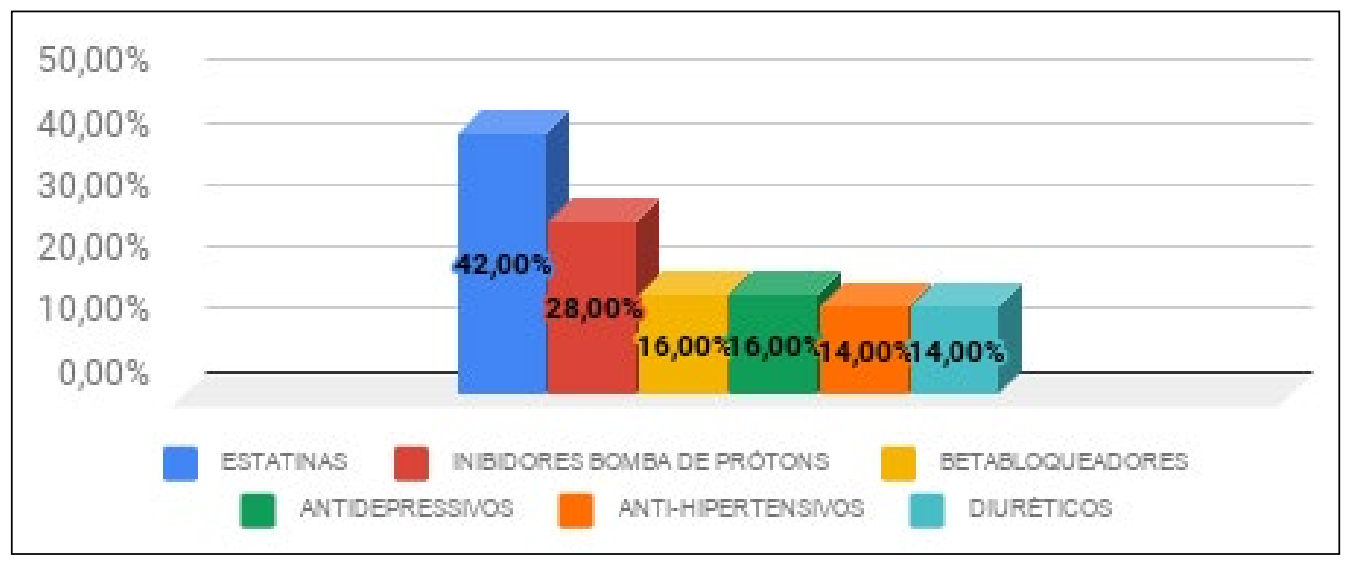

Ao serem questionados se sabiam o que era uma planta medicinal, 94\% disseram que sim, e ao explicarem sobre o conceito, a maioria respondeu ser um chá. A maioria dos entrevistados (62\%) considera que as plantas medicinais são naturais, por isso não oferecem riscos à saúde. Dentre os que acreditam que as plantas podem ter efeitos colaterais, $44 \%$ responderam que estas fazem menos mal que os medicamentos convencionais e 10\% relataram que elas podem fazer tão mal quanto um medicamento convencional.

O fato da maioria dos entrevistados acreditarem no mito "natural não faz mal", gera uma certa preocupação, pois é fundamental compreender que, se o produto for natural, pode sim colocar em risco a saúde da população. Schiavo (2017), concluiu em seu estudo, que 50\% das entrevistadas pensavam que as plantas não fazem mal à saúde, já Silva, Almeida e Rocha (2015), observaram que $82 \%$ da população estudada imaginava que as plantas medicinais fazem menos mal que os medicamentos convencionais.

Foram listadas 46 espécies de plantas utilizadas, distribuídas em 29 famílias botânicas, sendo a família Asteraceae a mais representativa neste estudo, com 7 espécies citadas pela população. No Quadro I estão apresentadas as plantas mencionadas pelos entrevistados e respectivas famílias botânicas, espécies, indicações terapêuticas, parte utilizada e modo de preparo.

Quadro I - Plantas medicinais citadas pelos usuários conforme nome popular, espécie, família, uso terapêutico, modo de preparo e parte utilizada

\begin{tabular}{|c|c|c|c|c|c|}
\hline $\begin{array}{c}\text { Nome } \\
\text { popular }\end{array}$ & Família & Espécie & Uso terapêutico & $\begin{array}{c}\text { Modo de } \\
\text { preparo }\end{array}$ & $\begin{array}{c}\text { Parte } \\
\text { utilizada }\end{array}$ \\
\hline Açoita-cavalo & Malvaceae & Luehea divaricata & câncer de próstata & infusão & casca \\
\hline Alcachofra & Asteraceae & Cynara scolymus & colesterol, tireóide & infusão & folhas \\
\hline Alecrim & Lamiaceae & $\begin{array}{c}\text { Rosmarinus } \\
\text { officinalis }\end{array}$ & $\begin{array}{c}\text { mal estar, } \\
\text { reumatismo }\end{array}$ & infusão & $\begin{array}{c}\text { talos, } \\
\text { folhas }\end{array}$ \\
\hline
\end{tabular}




\begin{tabular}{|c|c|c|c|c|c|}
\hline $\begin{array}{l}\text { Nome } \\
\text { popular }\end{array}$ & Família & Espécie & Uso terapêutico & $\begin{array}{l}\text { Modo de } \\
\text { preparo }\end{array}$ & $\begin{array}{c}\text { Parte } \\
\text { utilizada }\end{array}$ \\
\hline Anis-estrelado & Illiciaceae & Illicium verum & gripe, chimarrão & infusão & frutos \\
\hline Apartana & NE & $\mathrm{NE}$ & convulsão & infusão & folhas \\
\hline Arnica & Asteraceae & $\begin{array}{c}\text { Arnica } \\
\text { chamissonis }\end{array}$ & inflamação & infusão & folhas \\
\hline Arruda & Rutaceae & Ruta graveolens & infecção bexiga & infusão & folhas \\
\hline Babosa & Xanthorrhoeaceae & Aloe vera & $\begin{array}{c}\text { queimaduras, azia, } \\
\text { câncer }\end{array}$ & $\begin{array}{c}\text { passar na } \\
\text { queimadura, } \\
\text { com água fria } \\
\text { em jejum, } \\
\text { batido no } \\
\text { liquidificador }\end{array}$ & $\begin{array}{l}\text { miolo, } \\
\text { folhas }\end{array}$ \\
\hline Berinjela & Solanaceae & $\begin{array}{l}\text { Solanum } \\
\text { melongena }\end{array}$ & colesterol & $\begin{array}{l}\text { deixar uns } \\
\text { minutos em } \\
\text { água gelada }\end{array}$ & fruto \\
\hline Boldo & Lamiaceae & $\begin{array}{l}\text { Plectranthus } \\
\text { barbatus }\end{array}$ & fígado, estômago & infusão & folhas \\
\hline $\begin{array}{l}\text { Cabelo-de- } \\
\text { porco }\end{array}$ & Poaceae & $\begin{array}{l}\text { Piptochaetium } \\
\text { stipoides }\end{array}$ & rins, bexiga & infusão & folhas \\
\hline Camomila & Asteraceae & $\begin{array}{l}\text { Matricaria } \\
\text { recutita }\end{array}$ & $\begin{array}{l}\text { calmante, cólicas, } \\
\text { estômago, fígado }\end{array}$ & infusão & $\begin{array}{l}\text { flores, } \\
\text { folhas }\end{array}$ \\
\hline Cana-do-brejo & Costaceae & Costus spicatus & rins & infusão & folhas \\
\hline $\begin{array}{l}\text { Canela-de- } \\
\text { velho }\end{array}$ & Melastomataceae & Miconia albicans & $\begin{array}{c}\text { dores nas } \\
\text { articulações }\end{array}$ & infusão & folhas \\
\hline Capim-limão & Poaceae & $\begin{array}{l}\text { Cymbopogon } \\
\text { citratus }\end{array}$ & $\begin{array}{c}\text { pedra nos rins, } \\
\text { febre, baixar } \\
\text { pressão, estômago, } \\
\text { calmante, chimarrão }\end{array}$ & $\begin{array}{l}\text { decocção, } \\
\text { infusão e } \\
\text { maceração }\end{array}$ & folhas \\
\hline Carqueja & Asteraceae & $\begin{array}{l}\text { Baccharis } \\
\text { trimera }\end{array}$ & emagrecer, fígado & $\begin{array}{l}\text { decocção e } \\
\text { batido no } \\
\text { liquidificador } \\
\text { com água } \\
\end{array}$ & folhas \\
\hline $\begin{array}{l}\text { Catinga-de- } \\
\text { mulata }\end{array}$ & Asteraceae & $\begin{array}{l}\text { Tanacetum } \\
\text { vulgare }\end{array}$ & estômago & infusão & folhas \\
\hline Cavalinha & Equisetum & Equisetaceae & infecção & infusão & folhas \\
\hline Chá-de-bugre & Boraginaceae & Cordia salicifolia & inflamação & infusão & folhas \\
\hline Cipreste & Cupressaceae & $\begin{array}{c}\text { Cupressus } \\
\text { sempervirens }\end{array}$ & $\begin{array}{c}\text { infecção boca ou } \\
\text { estômago,pedra nos } \\
\text { rins }\end{array}$ & infusão & folhas \\
\hline Chuchu & Curcubitaceae & Sechium edule & pressão & infusão & folhas \\
\hline Endro & Apiaceae & $\begin{array}{l}\text { Anethum } \\
\text { graveolens }\end{array}$ & calmante & infusão & folhas \\
\hline $\begin{array}{c}\text { Erva-de-santa- } \\
\text { luzia } \\
\end{array}$ & Commelinaceae & Commelina erecta & $\begin{array}{l}\text { calmante, } \\
\text { inflamação }\end{array}$ & infusão & folhas \\
\hline Erva-tostão & Nyctaginaceae & Boerhavia hirsuta & bexiga, rins & infusão & folhas \\
\hline $\begin{array}{l}\text { Espinheira- } \\
\text { santa }\end{array}$ & Celastraceae & Maytenus ilicifolia & $\begin{array}{c}\text { inflamação, limpar } \\
\text { o sangue }\end{array}$ & infusão & folhas \\
\hline Funcho & Apiaceae & $\begin{array}{l}\text { Foeniculum } \\
\text { vulgare }\end{array}$ & $\begin{array}{l}\text { cólicas, gripe, } \\
\text { diurético }\end{array}$ & infusão & folhas \\
\hline
\end{tabular}




\begin{tabular}{|c|c|c|c|c|c|}
\hline $\begin{array}{l}\text { Nome } \\
\text { popular }\end{array}$ & Família & Espécie & Uso terapêutico & $\begin{array}{l}\text { Modo de } \\
\text { preparo }\end{array}$ & $\begin{array}{c}\text { Parte } \\
\text { utilizada }\end{array}$ \\
\hline Gengibre & Zingiberaceae & Zingiber officinale & bexiga & infusão & raíz \\
\hline Guabiroba & Myrtaceae & $\begin{array}{c}\text { Campomanesia } \\
\text { xanthocarpa }\end{array}$ & $\begin{array}{l}\text { aumentar a } \\
\text { imunidade }\end{array}$ & infusão & $\begin{array}{l}\text { folhas e } \\
\text { talo }\end{array}$ \\
\hline Hortelã & Lameaceae & Mentha piperita & gripe, chimarrão & infusão & folhas \\
\hline Insulina & Vitaceae & Cissus sicyoides & diabetes & infusão & folhas \\
\hline Laranjeira & Rutaceae & Citrus sinensis & $\begin{array}{l}\text { gripe, calmante, } \\
\text { estômago, bexiga }\end{array}$ & infusão & $\begin{array}{l}\text { folhas, } \\
\text { casca seca }\end{array}$ \\
\hline Losna & Asteraceae & $\begin{array}{l}\text { Artemisia } \\
\text { absinthium }\end{array}$ & $\begin{array}{c}\text { estômago, dor de } \\
\text { cabeça }\end{array}$ & $\begin{array}{l}\text { infusão e em } \\
\text { água gelada }\end{array}$ & $\begin{array}{l}\text { folhas e } \\
\text { raiz }\end{array}$ \\
\hline Louro & Lauraceae & Laurus nobilis & menopausa & infusão & folhas \\
\hline Malva & Malvaceae & Malva sylvestris & $\begin{array}{l}\text { infecção boca ou } \\
\text { estômago, gripe }\end{array}$ & $\begin{array}{l}\text { infusão e } \\
\text { maceração }\end{array}$ & folhas \\
\hline Manjerona & Lamiaceae & $\begin{array}{l}\text { Origanum } \\
\text { majorana }\end{array}$ & $\begin{array}{c}\text { colesterol, chá para } \\
\text { criança }\end{array}$ & infusão & folhas \\
\hline Manjericão & Ocimun & $\begin{array}{c}\text { Ocimum } \\
\text { americanum }\end{array}$ & cicatrizante & maceração & folhas \\
\hline Maracujá & Passifloraceae & Passiflora edulis & calmante & infusão & folhas \\
\hline Marcela & Asteraceae & $\begin{array}{l}\text { Achyrocline } \\
\text { satureioides }\end{array}$ & $\begin{array}{l}\text { digestão, pressão, } \\
\text { antibiótico, } \\
\text { calmante }\end{array}$ & infusão & flores \\
\hline Pega-pega & Fabaceae & $\begin{array}{l}\text { Desmodium } \\
\text { incanum }\end{array}$ & colesterol & infusão & folhas \\
\hline Poejo & Lamiaceae & $\begin{array}{l}\text { Mentha } \\
\text { pulegium }\end{array}$ & $\begin{array}{l}\text { gripe, chimarrão, } \\
\text { cólicas em bebês }\end{array}$ & $\begin{array}{c}\text { infusão e } \\
\text { maceração }\end{array}$ & folhas \\
\hline Pulmonária & Boraginaceae & $\begin{array}{l}\text { Pulmonaria } \\
\text { officinalis }\end{array}$ & pulmão & xarope & folhas \\
\hline Quebra-pedra & Phyllanthaceae & $\begin{array}{l}\text { Phyllanthus } \\
\text { acutifolius }\end{array}$ & rins, bexiga & infusão & flores \\
\hline Romã & Lythraceae & Punica granatum & diarréia & decocção & casca \\
\hline Salsa & Apiaceae & $\begin{array}{l}\text { Petroselinum } \\
\text { crispum }\end{array}$ & bexiga & infusão & raíz \\
\hline Sálvia & Lameaceae & Salvia officinalis & estômago & infusão & folhas \\
\hline Tansagem & Ginaceae & Plantago major & rins, bexiga & $\begin{array}{c}\text { infusão, } \\
\text { decocção e } \\
\text { batida no } \\
\text { liquidificador } \\
\text { com água }\end{array}$ & folhas \\
\hline
\end{tabular}

A principal forma de preparo citada foi a infusão. No estudo realizado por Schiavo (2017), 80\% da população estudada revelou utilizar a infusão, do mesmo modo que Santa Helena, Oliveira e Neves (2018), no estudo que avaliou o conhecimento e uso de plantas medicinais por usuários de unidades básicas de saúde do Paraná. Outras formas de preparo também citadas foram o uso da água gelada e do liquidificador ( 3 citações cada), somente uma pessoa citou o xarope como modo de preparo. 
A parte vegetal mais utilizada nas preparações foram as folhas $(76 \%)$, também foram citadas flores, cascas, raízes, frutos, talos e miolos. No estudo de Castellani (1999), as partes mais utilizadas foram as folhas, botões e flores, pois são ricas em componentes voláteis, aromas delicados e princípios ativos que se degradam pela ação combinada da água e do calor prolongado.

O hábito de tomar chimarrão, bebida tradicional da região Sul, também teve predominância, onde $80 \%$ disseram consumir com frequência, além de ser muito comum o uso de determinadas plantas no seu preparo para dar um sabor mais agradável à bebida, assim como nos estudos realizados por Schwambach e Amador (2007) e por Schiavo et al. 2017. A Ilex paraguariensis possui em sua composição compostos fenólicos, antioxidantes que agem protegendo o organismo de reações oxidativas, além de aminoácidos, vitaminas, saponinas e metilxantinas, sendo assim um composto estimulante e diurético (SIMÕES et al., 2002).

As espécies mais citadas neste levantamento foram: camomila (Matricaria recutita), marcela (Achyrocline satureioides), capim-limão (Cymbopogon citratus), boldo (Plectranthus barbatus), funcho (Foeniculum vulgare), malva (Malva sylvestris), laranjeira (Citrus sinensis), poejo (Mentha pulegium) e losna (Artemisia absinthium).

A camomila foi a planta mais mencionada, Matricaria recutita, e teve sua ação relacionada como calmante pela maioria dos usuários e os demais disseram utilizar como digestiva. O mesmo foi apontado por Pilla, Amorozo e Furlan (2006) em seu estudo que atribuíram sua utilização à propriedades sedativas e digestivas.

Em segundo lugar a marcela, Achyrocline satureioides, teve sua utilização relacionada à problemas digestivos e como calmante, e um dos participantes disse usá-la como antibiótico. Vendruscolo, Rates e Mentz (2005) também obtiveram resultados para as atividades anti-inflamatória, antiespasmódica, analgésica e sedativa. Quanto às atividades antibióticas, Simões (1984) faz relação da atividade microbiana com alguns flavonóides isolados da planta.

O capim-limão, Cymbopogon citratus, também conhecido como "ervacidreira", foi mais citado com finalidade para controlar a pressão alta. A finalidade anti-hipertensiva atribuída à esta planta é muito comum e encontrada em outros estudos, assim como nos de Schiavo (2017) e Brasileiro (2008), onde a população abordada também relatou a mesma finalidade relacionada à planta. Outros usuários relataram ação digestiva e calmante, assim como Ohno, Tomoyuki et al. (2003) descobriram em seu estudo que o óleo essencial desta planta pode ser utilizado para eliminar a bactéria Helicobacter pylori, e que a mesma não desenvolve resistência ao óleo. Já a ação sedativa (calmante) foi descrita por Ceolin (2009), em seus indivíduos estudados.

O boldo, Plectranthus barbatus, conhecido como falso-boldo, foi muito relacionado à tratamentos digestivos, assim como no estudo de Schultz et al. 
(2007), o qual relata a atividade inibitória da bomba H+, K+-ATPase gástrica por plectrinona $\mathrm{A}$, um constituinte diterpênico isolado desta espécie. As mesmas finalidades descritas também foi relata Badke et al. (2011).

A utilização do funcho, Foeniculum vulgare, foi citada para tratar cólicas e gripes, apenas um participante relatou usar como diurético. Os mesmos resultados podem ser observados no estudo de Grunwald e Janicke, (2009a) e Gori et al. (2012), no qual o funcho exerce efeitos benéficos a nível respiratório, diminuindo o muco existente, assim como a nível gastrointestinal na prevenção de flatulências, cólicas e espasmos. Sua ação diurética foi comprovada por Rahimi e Ardekani, (2013) onde a planta estudada apresentou capacidade antioxidante, diurética, anti-inflamatória, antimicrobiana, antibacteriana e estrogênica.

Outra planta bastante mencionada pela população no estudo foi a malva, Malva sylvestris, para tratar infecções e feridas na boca, dores de estômago e gripes, assim como relatado no trabalho de Kovalik et al. (2014) onde a planta apresentou um grande potencial anti-inflamatório. Já Razavi et al. (2011) descobriram importantes substâncias anti-inflamatórias tanto para o trato respiratório como para a epiderme.

O poejo, Mentha pulegium, teve sua maior indicação citada como sendo para gripe e alguns indivíduos citaram como calmante, principalmente para cólicas em bebês, assim como nos resultados encontrados na pesquisa de Ceolin (2009). Sua atividade respiratória foi mencionada pela população estudada por Sandri et al. (2007), onde os óleos essenciais desta planta demonstraram que a mesma possui um grande potencial antibacteriano.

A laranjeira, Citrus sinensis, foi outra planta muito apontada, sendo utilizada como calmante, para tratar a má digestão, dores na bexiga e resfriados. O óleo volátil da casca do fruto apresenta atividade sedativa e hipnótica, o extrato alcoólico da casca dos frutos possui efeito antiespasmódico, também já foram demonstradas atividade antimicrobiana in vitro e ação sobre o bem-estar e comportamento (CARVALHO-FREITAS; COSTA, 2002; VENDRUSCOLO et al., 2005; PULTRINI et al., 2006).

Por sua vez, a espécie Artemisia absinthium, conhecida popularmente como losna, foi relacionada à dores de estômago e dores de cabeça, assim como no estudo de Turak et al. (2014), onde as partes aéreas da planta foram utilizadas para preparações gástricas fitoterápicas. Outras propriedades biológicas também foram estudadas em Riahi et al. (2015) na qual os compostos do óleo essencial apresentou atividade antimicrobiana, acaricida, inseticida, anti-helmínticos, antisséptica e antiespasmódica.

Um ponto muito importante observado neste estudo, foi em relação à dificuldade de identificação das plantas devido à falta de conhecimento, como por exemplo, uma das entrevistadas relatou o uso de apartana para o tratamento de convulsões, no qual não foi possível identificar o nome correto 
da planta, pois não foram encontradas informações sobre a mesma. Outro fato comum é o uso de um mesmo nome popular para diferentes espécies, como é o caso do capim-limão, onde todos se referiram como cidreira, erva-cidreira ou cidró, outro exemplo foi atribuir o uso do medicamento Infalivina para se referir ao boldo, Plectranthus barbatus. No estudo de Brasileiro et al. (2008), foi relatado o mesmo problema, podendo ocorrer erros ou trocas entre as plantas, e até mesmo efeitos indesejáveis.

Um hábito muito comum entre os indivíduos estudados, foi o de não comunicar seu médico sobre o uso das plantas medicinais, o que pode gerar sérios riscos à saúde, pois podem interagir com alguns medicamentos prescritos podendo causar intoxicações. Mais da metade dos entrevistados disse que não informa ao médico sobre o uso, enquanto que $22 \%$ responderam que informam e $20 \%$ às vezes informa, o mesmo foi relatado nos estudo de Gonçalves (2017) e Júnior et al. (2012). Já sobre o uso de plantas medicinais junto com medicamentos, $64 \%$ responderam que não fazem o uso concomitantemente, $10 \%$ responderam que às vezes usam e $26 \%$ disseram não tomar este cuidado. O uso de plantas medicinais concomitantemente com medicamentos pode ocasionar grandes riscos à saúde da população, pois as mesmas são constituídas de compostos químicos, e se administradas simultaneamente com os medicamentos, podem causar interações medicamentosas, reduzindo ou potencializando os efeitos e comprometendo a eficácia de tratamentos (WILLIAMSON, 2005).

Vários medicamentos utilizados pelos participantes da pesquisa podem interagir com alguma das plantas medicinais citadas. Segue no Quadro II as plantas medicinais que mais interagem com os medicamentos mencionados neste estudo, conforme dados da literatura.

Quadro II - Interações entre plantas medicinais e medicamentos citados neste estudo comparadas com a literatura

\begin{tabular}{|c|c|c|c|c|}
\hline $\begin{array}{c}\text { Planta } \\
\text { medicinal }\end{array}$ & Interação & Efeito & Medicamento citado & Referência \\
\hline $\begin{array}{c}\text { Camomila } \\
\text { (Matricaria } \\
\text { recutita) }\end{array}$ & $\begin{array}{c}\text { Heparina, } \\
\text { anticoagulantes } \\
\text { orais e } \\
\text { antiagregantes } \\
\text { plaquetários }\end{array}$ & $\begin{array}{c}\text { Aumento do risco de } \\
\text { hemorragia }\end{array}$ & AAS & $\begin{array}{c}\text { WILLIAMSON; } \\
\text { DRIVER e } \\
\text { BAXTE, 2012 }\end{array}$ \\
\cline { 2 - 6 } & $\begin{array}{c}\text { Barbitúricos e } \\
\text { benzodiazepínicos }\end{array}$ & $\begin{array}{c}\text { Pode potencializar o } \\
\text { efeito sedativo destes } \\
\text { medicamentos }\end{array}$ & Clonazepam, Diazepam & $\begin{array}{c}\text { NICOLETTI, } \\
\text { 2007 }\end{array}$ \\
\cline { 2 - 6 } & $\begin{array}{c}\text { A presença de } \\
\text { mucilagens na planta } \\
\text { pode interferir na } \\
\text { absorção do fármaco, } \\
\text { podendo diminuir ou } \\
\text { metardar seu efeito }\end{array}$ & $\begin{array}{c}\text { Paracetamol, Enalapril, } \\
\text { Buscopan, Alopurinol, } \\
\text { Atorvastatina, } \\
\text { Omeprazol, etc }\end{array}$ & $\begin{array}{c}\text { NICOLETTI, } \\
\text { 2007 }\end{array}$ & \\
\hline
\end{tabular}




\begin{tabular}{|c|c|c|c|c|}
\hline $\begin{array}{c}\text { Planta } \\
\text { medicinal }\end{array}$ & Interação & Efeito & Medicamento citado & Referência \\
\hline $\begin{array}{l}\text { Hortelã } \\
\text { (Mentha } \\
\text { piperita) }\end{array}$ & $\begin{array}{l}\text { Sinvastatina, } \\
\text { felodipino }\end{array}$ & $\begin{array}{c}\text { Pode aumentar os } \\
\text { níveis sanguíneos } \\
\text { destes fármacos, o óleo } \\
\text { desta planta interfere } \\
\text { nas enzimas do } \\
\text { citocromo } \\
\text { P450, podendo } \\
\text { elevar o nível dos } \\
\text { medicamentos } \\
\text { intensificando seus } \\
\text { efeitos. }\end{array}$ & $\begin{array}{l}\text { Sinvastatina, } \\
\text { Rosuvastatina }\end{array}$ & ANVISA, 2018 \\
\hline $\begin{array}{l}\text { Malva } \\
\text { (Malva } \\
\text { sylvestris) }\end{array}$ & $\mathrm{NE}$ & - & $\begin{array}{c}\text { Diclofenaco de potássio, } \\
\text { Ibuprofeno, Sinvastatina, } \\
\text { Metformina, } \\
\text { Levotiroxina, etc }\end{array}$ & - \\
\hline $\begin{array}{c}\text { Marcela } \\
\text { (Achyrocline } \\
\text { satureioides) }\end{array}$ & $\mathrm{NE}$ & - & $\begin{array}{c}\text { Diclofenaco de potássio, } \\
\text { Dipirona, Clonazepam, } \\
\text { Anlodipino, Citalopram, } \\
\text { AAS } \\
\end{array}$ & - \\
\hline $\begin{array}{l}\text { Laranjeira } \\
\text { (Citrus } \\
\text { sinensis) }\end{array}$ & NE & - & $\begin{array}{l}\text { Doxazosina, } \\
\text { Finasterida }\end{array}$ & - \\
\hline $\begin{array}{c}\text { Chuchu } \\
\text { (Sechium edule) }\end{array}$ & Anti hipertensivos & $\begin{array}{l}\text { O mecanismo pelo } \\
\text { qual esta interação } \\
\text { ocorre não foi } \\
\text { encontrado }\end{array}$ & Enalapril & $\begin{array}{l}\text { MAIA et al., } \\
2011\end{array}$ \\
\hline $\begin{array}{l}\text { Capim-limão } \\
\text { (Cymbopogon } \\
\text { citratus) }\end{array}$ & $\begin{array}{l}\text { Medicamentos } \\
\text { sedativos }\end{array}$ & $\begin{array}{c}\text { Pode aumentar o efeito } \\
\text { dos medicamentos } \\
\text { sedativos }\end{array}$ & $\begin{array}{l}\text { Clonazepam, } \\
\text { Diazepam }\end{array}$ & BRASIL, 2016 \\
\hline \multirow[t]{3}{*}{$\begin{array}{c}\text { Boldo } \\
\text { (Plectranthus } \\
\text { barbatus) }\end{array}$} & Anti Glicêmicos & $\begin{array}{l}\text { Estímulo à liberação de } \\
\text { insulina }\end{array}$ & Metformina & $\begin{array}{l}\text { GELATTI; } \\
\text { OLIVEIRA e } \\
\text { COLET, } 2016 \\
\end{array}$ \\
\hline & $\begin{array}{l}\text { Hidroclorotiazida, } \\
\text { Drospirenona, } \\
\text { Propranolol } \\
\end{array}$ & $\begin{array}{c}\text { Aumenta os efeitos } \\
\text { destes medicamentos }\end{array}$ & Hidroclorotiazida & $\begin{array}{l}\text { GELATTI; } \\
\text { OLIVEIRA e } \\
\text { COLET, } 2016 \\
\end{array}$ \\
\hline & Anticoagulantes & $\begin{array}{l}\text { Aumenta os riscos de } \\
\text { hemorragias }\end{array}$ & AAS & $\begin{array}{l}\text { NICOLETTI, } \\
2007\end{array}$ \\
\hline $\begin{array}{c}\text { Arruda } \\
\text { (Ruta } \\
\text { graveolens })\end{array}$ & NE & - & $\begin{array}{c}\text { AAS, Sinvastatina, } \\
\text { Omeprazol, Metoprolol }\end{array}$ & - \\
\hline $\begin{array}{l}\text { Funcho } \\
\text { (Foeniculum } \\
\text { vulgare) }\end{array}$ & $\begin{array}{l}\text { Medicamentos } \\
\text { que sofrem } \\
\text { metabolização } \\
\text { hepática }\end{array}$ & $\begin{array}{l}\text { Furanocumarinas } \\
\text { podem inibir a } \\
\text { atividade de enzimas } \\
\text { de metabolização } \\
\text { CIP3A4 e CIP2D6 }\end{array}$ & Omeprazol & BRASIL, 2016 \\
\hline $\begin{array}{l}\text { Catinga-de- } \\
\text { mulata } \\
\text { (Tanacetum } \\
\text { vulgare) }\end{array}$ & $\mathrm{NE}$ & - & $\begin{array}{c}\text { AAS, Sinvastatina, } \\
\text { Omeprazol, Metoprolol }\end{array}$ & - \\
\hline
\end{tabular}




\begin{tabular}{|c|c|c|c|c|}
\hline $\begin{array}{l}\text { Planta } \\
\text { medicinal }\end{array}$ & Interação & Efeito & Medicamento citado & Referência \\
\hline $\begin{array}{l}\text { Insulina } \\
\text { vegetal } \\
\text { (Cissus } \\
\text { sicyoides) }\end{array}$ & NE & - & $\begin{array}{c}\text { AAS, Sinvastatina, } \\
\text { Omeprazol, Metoprolol }\end{array}$ & - \\
\hline $\begin{array}{l}\text { Alecrim } \\
\text { (Rosmarinus } \\
\text { officinalis) }\end{array}$ & $\begin{array}{l}\text { Diuréticos, } \\
\text { laxantes e anti- } \\
\text { hipertensivos }\end{array}$ & $\begin{array}{l}\text { O mecanismo pelo } \\
\text { qual esta interação } \\
\text { ocorre não foi } \\
\text { encontrado }\end{array}$ & Atenolol, Clonidina & $\begin{array}{l}\text { PAIXÃO et al., } \\
2016\end{array}$ \\
\hline $\begin{array}{l}\text { Cipreste } \\
\text { (Cupressus } \\
\text { sempervirens) }\end{array}$ & NE & & Paracetamol & - \\
\hline $\begin{array}{l}\text { Açoita-cavalo } \\
\text { (Luehea } \\
\text { divaricata) } \\
\end{array}$ & NE & - & Paracetamol, Ibuprofeno & - \\
\hline $\begin{array}{l}\text { Pega-pega } \\
\text { (Desmodium } \\
\text { incanum) }\end{array}$ & NE & - & Paracetamol, Ibuprofeno & - \\
\hline $\begin{array}{c}\text { Louro } \\
\text { (Laurus nobilis) }\end{array}$ & NE & - & Tramadol & - \\
\hline $\begin{array}{c}\text { Erva-de-santa- } \\
\text { luzia } \\
\text { (Commelina } \\
\text { erecta })\end{array}$ & NE & - & $\begin{array}{c}\text { Paracetamol, Omeprazol, } \\
\text { Furosemida }\end{array}$ & - \\
\hline $\begin{array}{l}\text { Manjerona } \\
\text { (Origanum } \\
\text { majorana) }\end{array}$ & NE & - & $\begin{array}{l}\text { Sinvastatina, Citalopram, } \\
\text { Alendronato de sódio, } \\
\text { Diclofenaco de potássio }\end{array}$ & - \\
\hline \multirow[t]{2}{*}{$\begin{array}{l}\text { Gengibre } \\
\text { (Zingiber } \\
\text { officinale) }\end{array}$} & Antiglicêmico & $\begin{array}{c}\text { Agentes } \\
\text { hipoglicemiantes }\end{array}$ & Metformina & $\begin{array}{c}\text { NEWALL; } \\
\text { ANDERSON e } \\
\text { PHILLIPSON, } \\
2002\end{array}$ \\
\hline & $\begin{array}{c}\text { Antiplaquetários } \\
\text { e anticoagulantes, } \\
\text { AINES e inibidores } \\
\text { da COX-2 }\end{array}$ & $\begin{array}{l}\text { Pode aumentar os } \\
\text { riscos de hemorragia }\end{array}$ & Diclofenaco de potássio & $\begin{array}{l}\text { LAMBRECHT et } \\
\text { al., } 2000 \\
\text { NICOLETTI, } \\
2007\end{array}$ \\
\hline $\begin{array}{l}\text { Endro } \\
\text { (Anethum } \\
\text { graveolens) }\end{array}$ & NE & - & $\begin{array}{l}\text { Paracetamol, } \\
\text { Dipirona, Omeprazol, } \\
\text { Metoclopramida }\end{array}$ & - \\
\hline $\begin{array}{l}\text { Tansagem } \\
\text { (Plantago } \\
\text { major) }\end{array}$ & $\begin{array}{c}\text { Todos os } \\
\text { medicamentos }\end{array}$ & $\begin{array}{l}\text { A presença de } \\
\text { mucilagens na planta } \\
\text { pode interferir na } \\
\text { absorção do fármaco, } \\
\text { podendo diminuir ou } \\
\text { retardar seu efeito }\end{array}$ & $\begin{array}{c}\text { Metformina, Metoprolol, } \\
\text { Rosuvastatina, } \\
\text { Enalapril, Pantoprazol, } \\
\text { Cinarizina, Bromazepam, } \\
\text { Diclofenaco de Potássio }\end{array}$ & $\begin{array}{c}\text { NEWALL; } \\
\text { ANDERSON e } \\
\text { PHILLIPSON, } \\
2002 \\
\text { ROSSATO et al., } \\
2012\end{array}$ \\
\hline $\begin{array}{l}\text { Anis estrelado } \\
\text { (Illicium } \\
\text { verum) }\end{array}$ & NE & - & $\begin{array}{l}\text { Metformina, Enalapril, } \\
\text { Rosuvastatina, } \\
\text { Pantoprazol }\end{array}$ & - \\
\hline $\begin{array}{l}\text { Salsa } \\
\text { (Petroselinum } \\
\text { crispum) }\end{array}$ & NE & - & Paracetamol & - \\
\hline
\end{tabular}




\begin{tabular}{|c|c|c|c|c|}
\hline $\begin{array}{l}\text { Planta } \\
\text { medicinal }\end{array}$ & Interação & Efeito & Medicamento citado & Referência \\
\hline $\begin{array}{l}\text { Pulmonária } \\
\text { (Pulmonaria } \\
\text { officinalis) }\end{array}$ & NE & - & $\begin{array}{l}\text { Atenolol, Sinvastatina, } \\
\text { Complexo B, Loratadina }\end{array}$ & - \\
\hline $\begin{array}{c}\text { Cana do brejo } \\
\text { (Costus } \\
\text { spicatus) }\end{array}$ & NE & - & $\begin{array}{l}\text { Alendronato de } \\
\text { Sódio, Pantoprazol, } \\
\text { Clonazepam }\end{array}$ & - \\
\hline $\begin{array}{l}\text { Chá de bugre } \\
\text { (Cordia } \\
\text { salicifolia) } \\
\end{array}$ & NE & - & $\begin{array}{c}\text { Alendronato de } \\
\text { Sódio, Pantoprazol, } \\
\text { Clonazepam }\end{array}$ & - \\
\hline $\begin{array}{l}\text { Canela de } \\
\text { velho } \\
\text { (Miconia } \\
\text { albicans) }\end{array}$ & NE & - & $\begin{array}{l}\text { Alendronato de } \\
\text { Sódio, Pantoprazol, } \\
\text { Clonazepam }\end{array}$ & - \\
\hline $\begin{array}{c}\text { Guabiroba } \\
\text { (Campomanesia } \\
\text { xanthocarpa) }\end{array}$ & $\mathrm{NE}$ & - & $\begin{array}{c}\text { Alendronato de } \\
\text { Sódio, Pantoprazol, } \\
\text { Clonazepam }\end{array}$ & - \\
\hline $\begin{array}{l}\text { Manjericão } \\
\text { (Ocimum } \\
\text { americanum) }\end{array}$ & NE & - & $\begin{array}{l}\text { Omeprazol, Diclofenaco } \\
\text { de potássio }\end{array}$ & - \\
\hline $\begin{array}{c}\text { Cabelo de } \\
\text { porco } \\
\text { (Piptochaetium } \\
\text { stipoides) }\end{array}$ & NE & - & Sertralina, Alopurinol & - \\
\hline $\begin{array}{l}\text { Erva tostão } \\
\text { (Boerhavia } \\
\text { hirsuta) }\end{array}$ & Anti-hipertensivos & $\begin{array}{l}\text { Altera a pressão } \\
\text { arterial }\end{array}$ & Hidroclorotiazida & $\begin{array}{l}\text { LORENZI e } \\
\text { MATOS, } 2008\end{array}$ \\
\hline
\end{tabular}

Com base nas interações descritas no Quadro II, existe a necessidade de orientar a população sobre o uso correto das plantas medicinais, uma vez que tanto a camomila (Matricaria recutita), quanto a tansagem (Plantago major), causam interações com todos os medicamentos citados.

As interações medicamentosas podem reduzir ou potencializar a atividade e efetividade do fármaco, podendo ser responsável pelo agravamento de algumas doenças, efeitos indesejáveis e fracasso terapêutico. A maioria das interações presentes neste estudo envolvem medicamentos de uso crônico, o que expõe a população a interações por longos períodos, exatamente por este motivo é tão importante informar ao médico sobre o uso de plantas medicinais concomitante a medicamentos, pois com essas informações o médico pode optar por medicamentos que não interajam com as plantas utilizadas, além de sugerir a substituição do chá para evitar interações com os medicamentos utilizados.

\section{CONCLUSÃO}

O emprego de plantas medicinais ainda é uma prática muito comum na comunidade estudada, influenciada principalmente pelos familiares, onde 
esse hábito é passado de geração para geração e a obtenção destas vêm de suas próprias residências.

O livre acesso às plantas, como por exemplo, em supermercados, farmácias e cultivadas em seus quintais, fazem a população acreditar que orientações sobre o uso são desnecessárias, pois acham que o que é natural não faz mal à saúde, mas muitas plantas medicinais associadas à medicamentos podem levar a sérias consequências, efeitos colaterais, interações e intoxicações sem precedentes.

Diante disso, existe a necessidade da orientação de profissionais da área da saúde para garantir a correta orientação à população sobre a eficácia e segurança das plantas medicinais, bem como, estabelecer uma relação entre saberes populares e conhecimento científico, para que seu uso racional seja difundido, conforme preconiza a Organização Mundial de Saúde.

\section{REFERÊNCIAS}

ANVISA. Formulário de Fitoterápicos Farmacopéia Brasileira. $1^{\circ}$ edição. $1^{\circ}$ suplemento. 2018. Disponível em: http:/ / portal.anvisa.gov.br/ documents/33832/259456/Suplemento+FFFB.pdf/478d1f83-7a0d-48aa-9815$37 \mathrm{dbc} 6 \mathrm{~b} 29 \mathrm{f} 9 \mathrm{a}$

BADKE, M. R. et al. Saberes e práticas populares de cuidado em saúde com o uso de plantas medicinais. Texto Contexto Enferm. Florianópolis, v. 21, n. 2, p. 363-370, Abr-jun 2012. Disponível em: <http:/ / www.scielo.br/scielo. php?pid=S010407072012000200014\&script=sci_abstract\&tlng=pt

BRASIL. Ministério da saúde. Política Nacional de Práticas Integrativas e Complementares do SUS. Brasília. 2006a. Disponível: http:/ /bvsms.saude.gov.br/ bvs/publicacoes/pnpic.pdf

BRASIL. Política Nacional de Plantas Medicinais e Fitoterápicos. Brasília: Ministério da Saúde; Secretaria de Ciência, Tecnologia e Insumos Estratégico. Departamento de Assistência Farmacêutica, 2006b. Disponível em: http:/ /bvsms.saude.gov.br/bvs/ publicacoes/politica_nacional_fitoterapicos.pdf>

BRASIL. Ministério da saúde. MS elabora relação de Plantas Medicinais de interesse do SUS. 2009. Disponível em: http:/ /bvsms.saude.gov.br/bvs/sus/pdf/marco/ ms_relacao_plantas_medicinais_sus_0603.pdf

BRASIL. RESOLUÇÃO - RDC N 10 DE 9 DE MARÇO DE 2010 - Dispõe sobre a notificação de drogas vegetais junto à Agência Nacional de Vigilância Sanitária (ANVISA) e dá outras providências. 2010. Disponível em: http:/ / bvsms.saude.gov. br/bvs/saudelegis/anvisa/2010/res0010_09_03_2010.html

BRASIL. Plantas medicinais e fitoterápicas: guia rápido para a utilização de algumas espécies vegetais. 2. ed. Brasília: Universidade de Brasília, 2016. Disponível em: 
https://www.researchgate.net/publication/319653640_PLANTAS_MEDICINAIS_E_ FITOTERAPICOS_GUIA_RAPIDO_PARA_A_UTILIZACAO_DE_ALGUMAS_ ESPECIES_VEGETAIS_-_2a_Ed

BRASILEIRO, B. G. et al. Plantas medicinais utilizadas pela população atendida no "Programa de Saúde da Família", Governador Valadares, MG, Brasil. Revista Brasileira de Ciências Farmacêuticas. v. 44, n. 4, out./dez., 2008. Disponível em:<http:/ / www.scielo.br/scielo.php?pid=S1516-93322008000400009\&script=sci_ abstract\&tlng=pt>

CARVALHO-FREITAS, M. I. R.; COSTA, M. Anxiolytic and sedative effects of extracts and essential oil from Citrus aurantium L. Biological \& Pharmaceutical Bulletin, v.25, n.12, p.1629-1633, 2002. Disponível em: http:/ / www.interscienceplace.org/isp/ index.php/isp/article/view/164/162

CASTELLANI, D. C. Plantas medicinais. Viçosa: Agromídia software, 1999.

Disponível em: https://www.redalyc.org/pdf/4457/445744077003.pdf

CEOLIN, T. et al. Plantas medicinais utilizadas como calmantes por agricultores ecológicos da região Sul do Rio Grande do Sul, Brasil. Rev.Enferm. UFPE online. v. 3, n. 4, p. 1034-1041, 2009. Disponível em: https:/ / periodicos.ufpe.br/revistas / revistaenfermagem/article/view/5599

GRUNWALD, J. e JANICKE, C. (2009a). A farmácia verde. Disponível em: https:/ / bdigital.ufp.pt/bitstream/10284/4077/1/Sara\%20Figueir\%C3\%B4a\%20da\%20 Silva $\% 20$ Martins $\% 20$ da $\% 20$ Concei $\%$ C3\%A7\%C3\%A3o\%20tese $\% 20$ alterada.pdf

GELATTI, G. T.; OLIVEIRA, K. R.; COLET, C. F. Potenciais interações relacionadas ao uso de medicamentos, plantas medicinais e fitoterápicos em mulheres no período do climatério. Revista de Pesquisa Cuidado é Fundamental. Rio de Janeiro. v.8, n.2, p.4328-4346, abr./jun. 2016. Disponível em: <http:/ /www.seer.unirio.br/index.php/ cuidadofundamental/article/view/4401>

GONÇALVES, RN. Práticas integrativas na Atenção Primária à Saúde, sob a ótica da fitoterapia. Dissertação (mestrado). Programa de pós-graduação em saúde coletiva. Setor de ciências da saúde. Universidade federal do paraná, p. 192. Curitiba, 2017. Disponível em: https:/ / acervodigital.ufpr.br/bitstream/handle/1884/56461/R\%20 -\%20E\%20-\%20FABIOLA \%20DA\%20ROSA\%20LUZ.pdf?sequence=1\&isAllowed=y

GORI, L., GALLO, E., MASCHERINI, V., MUGELLI, A., VANNACCI, A. e FIRENZUOLI, F. (2012). Can estragole in fennel seed decoctions really be considered a danger for human health? A fennel safety update. Evid Based Complement Alternat Med, pp. 1-22. Disponível em: https:/ /bdigital.ufp.pt/ bitstream/10284/4077/1/Sara\%20Figueir\%C3\%B4a\%20da\%20Silva\%20Martins\%20 da\%20Concei $\%$ C3\%A7\%C3\%A3o\%20tese $\% 20$ alterada.pdf

JUNIOR V. F. V., PINTO A. C., MACIEL M. A. M. Plantas medicinais, cura segura? Química Nova, São Paulo, v.28 n.3, p. 1-5, Maio/Junho, 2005. Disponível em: http:/ / co.unicaen.com.br:89/periodicos/index.php/UNICA/article/view/29/34 
JUNIOR, R. G. O.; LAVOR, E. M.; OLIVEIRA, M. R.; SOUZA, E. V.; SILVA, M. A.; SILVA, M. T. N. M. e NUNES, L. M. N. Plantas medicinais utilizadas por um grupo de idosos do município de Petrolina, Pernambuco. Revista eletrônica de farmácia. v.9,p. 16 - 28, 2012. Disponível em: https:/ / acervodigital.ufpr.br/bitstream/ handle/1884/56461/R\%20-\%20E\%20-\%20FABIOLA\%20DA\%20ROSA\%20LUZ. pdf?sequence $=1 \&$ is Allowed $=\mathrm{y}$

KOVALIK, A. C.; BISETTO, P.; POCHAPSKI, M. T.; CAMPAGNOLI, E. B.; PILATTI, G. L. e SANTOS, F. A. Effects of an orabase formulation with ethanolic extract of Malva sylvestris L. in oral wound healing in rats. J Med Food. 2014;17(5):618-24. Disponível em: https:/ / seer.imed.edu.br/index.php/JOI/article/view /1243/798

LAMBRECHT, J.E.; HAMILTON, W.; RABINOVICH, A. A Review of Herb Drug Interactions: Documented and Theoretical. Pharmacist, v.25, n.:8, 2000. Disponível em: <http://www.uspharmacist.com/oldformat.asp?url=newlook/files/comp/aug00alt. htm>

LORENZI, H.; MATOS, F. J. A. Plantas medicinais no Brasil: nativas e exóticas. 2. ed. São Paulo: Instituto Plantarum; 2008. 544 p. Disponível em: http:/ / repositorio.unesc. net/bitstream/1/618/1/Katrine\%20Teixeira.pdf

MAIA, L. F.; CASTRO, Q. J. T.; RESENDE, F. M. F.; RODRIGUES-DAS-DORES, R. G. Plantas medicinais e hipertensão. Pharm Rev.2011; 24:24-25. Disponível em: http:/ / oaji.net/articles/2017/3425-1515149047.pdf

MARAVAI, S. G.; COSTA, C. S.; LEFCHAKO, F. J.; MARTINELLO, O.B.; BECKER, I. R. T. e ROSSATO, A. E. Plantas medicinais: percepção, utilização e indicações terapêuticas de usuários da estratégia saúde da família do município de Criciúma SC vinculados ao pet- saúde. Arquivos catarinenses de medicina. vol. 40, n. 4, 2011. Disponível em: https:// acervodigital.ufpr.br/bitstream/handle/1884/56461/R\%20 -\%20E\%20-\%20FABIOLA \%20DA\%20ROSA \%20LUZ.pdf?sequence=1\&isAllowed=y

MORAES, M. E. A.; SANTANA, G. S. M. Aroeirado-sertão: um canditado promissor para o tratamento de úlceras gástricas. Funcap, v. 3, p. 5-6, 2001.

NEWALL, C. A.; ANDERSON L. A.; PHILLIPSON J. D. Plantas medicinais: guia para profissionais da saúde. Editorial Premier. São Paulo. 2002.

NICOLETTI, M. A.; OLIVEIRA-JÚNIOR, M. S. A.; BERTASSO, C. C.; CAPOROSSI; P. Y. e TAVARES, A. P. L. Principais interações no uso de medicamentos fitoterápicos. Infarma. 2007;19(1/2):32-40.

ODY, P. The complete medicinal herbal. Nova Iorque: Dorling Kindersley; 1993. 192p.

OHNO, T.; KITA, M.; YAMAOKA, Y.; IMAMURA, S.; MITSUUFUJI, S.; KODAMA, T.; KASHIRA, K. e IMANISHI, J. (1 de junho de 2003). Antimicrobial activity of essential oils against Helicobacter pylori. Helicobacter. 8 (3): 207-215. ISSN 1083-4389. PMID 12752733. Disponível em: https:/ / www.ncbi.nlm.nih.gov/pubmed/12752733 
PAIXÃO, J. A. et al. Levantamento bibliográfico de plantas medicinais comercializadas em feiras da Bahia e suas interações medicamentosas. Revista Eletrônica de Farmácia, v. 13, n. 2, p. 71-81, 2016. Disponível em: https:/ /www.revistas.ufg.br/REF/article/ view /35942

PILLA, M. A. C.; AMOROZO, M. C. M.; FURLAN, A. Obtenção e uso das plantas medicinais no distrito de Martim Francisco, Município de Mogi-Mirim, SP, Brasil. Acta Botanica Brasilica. v.20, n. 4, p. 789-802, 2006. Disponível em: http:/ /www. scielo.br/pdf/\%0D/abb/v20n4/05.pdf

PULTRINI, A. M.; GALINDO, L. A.; COSTA, M. Effects of the essential oil from Citrus aurantium L. in experimental anxiety models in mice. Life Sciences, v.78, p.1720-1725, 2006. Disponível em: http:/ / www.interscienceplace.org/isp/index.php/isp/article/ view/164/162

RAHIMI, R. e ARDEKANI, S. R. M. (2013). Medicinal properties of Foeniculum vulgare Mill. in tradicional Irian Medicine and Moderne Phytotherapy. Chin J Integr Med, 19, pp. 73-79. Disponível em: https://bdigital.ufp.pt/ bitstream/10284/4077/1/Sara\%20Figueir\%C3\%B4a\%20da\%20Silva\%20Martins\%20 da $\% 20$ Concei $\%$ C3\%A7\%C3\%A3o\%20tese $\% 20$ alterada.pdf

RAZAVI, S. M.; ZARRINI, G.; MOLAVI, G.; GHASEMI, G. Bioactivity of Malva Sylvestris L., a Medicinal Plant from Iran. Iran J Basic Med Sci. 2011;14(6):574-9. Disponível em: https:/ / seer.imed.edu.br/index.php/JOI/article/view/1243/798

RIAHI, L.; GHAZGHAZI, H.; AYARI, B.; AOUADHI, C.; KLAY, I.; CHOGRANI, H.; CHERIF, A.; ZOGHLAMI, N. Effect of environmental conditions on chemical polymorphism and biological activities among Artemisia absinthium L. essential oil provenances grown in Tunisia. Industrial Crops and Products, v. 66, n. 1, p. 96-102, 2015. Disponível em: https:/ /agrogeoambiental.ifsuldeminas.edu.br/index.php/ Agrogeoambiental/article/view/1082/pdf

ROSSATO, A. E. et al. Fitoterapia Racional: Aspectos Taxonômicos, Agroecológicos, Etnobotânicos e Terapêuticos. Editora DIOESC, $1^{\circ}$ edição. vol. 1, Florianópolis. 2012.

SANDRI, I. G.; ZACARIA, J.; FRACARO, F. e DELAMARE, A. P. L., Echeverrigaray $S$. Antimicrobial activity of the essential oils of Brazilian species of the genus Cunila against foodborne pathogens and spoiling bacteria. Food Chemistry 2007; 103: 823-828. Disponível em: http:/ / repositorio.unesc.net/bitstream/1/720/1/ Mar\%C3\%ADlia\%20Schutz\%20Borges.pdf

SANTA HELENA, E. T.; OLIVEIRA, V. C.; NEVES J. O. R. Polifarmácia e padrão de utilização de medicamentos em Pomerode, SC. Arquivos Catarinenses de Medicina, v. 47, n. 2, p. 124-136, 2018. Disponível em: http://www.acm.org.br/acm/seer/index. php/arquivos/article/view/328/257

SCHIAVO, M. et al. Conhecimento sobre plantas medicinais por mulheres em processo de envelhecimento. Semina: Ciências Biológicas e da Saúde, v. 38, n. 1, p. 
45-60, 2017. Disponível em: http:/ / www.uel.br/revistas/uel/index.php/seminabio/ article/view/27279/22633

SCHULTZ, C.; BOSSOLANI, M.P.; TORRES, L.M.B.; LIMA-LANDMAN, M.T.R.; LAPA, A.J.; SOUCCAR, C. Inhibition of the gastric $\mathrm{H}+, \mathrm{K}+-\mathrm{ATPase}$ by plectrinone A, a diterpenoid isolated from Plectranthus barbatus Andrews. Journal of Ethnopharmacology, v.111, n.1, p.1-7, 2007. Disponível em: http://www. interscienceplace.org/isp/index.php/isp/article/view/164/162

SCHWAMBACH, K. H. e AMADOR, T. A. Estudo da utilização de plantas medicinais e medicamentos em um município do sul do Brasil. Latin American Journal of Pharmacy, v. 26, n. 4, p.602, 2007. Disponível em: https:/ /www.researchgate. net/profile/Tania_Amador/publication/271850870_Estudo_da_Utilizacao_de_ Plantas_Medicinais_e_Medicamentos_em_um_Municipio_do_Sul_do_Brasil/ links /54d4f1b90cf2970e4e63f2ca/Estudo-da-Utilizacao-de-Plantas-Medicinais-eMedicamentos-em-umMunicipio-do-Sul-do-Brasil.pdf

SILVA, R. P.; ALMEIDA, A. K. P.; ROCHA, F. A. G. Os riscos em potencial do uso indiscriminado de plantas medicinais. V Congresso Norte Nordeste de Pesquisa e Inovação. 2015. Disponível em: <http:/ / congressos.ifal.edu.br/index.php/connepi / CONNEPI2010/paper/viewFile/676/407>

SIMÕES, C.M.O. Investigação químico-farmacológica de Achyrocline satureioides (Lam.) D.C., Compositae ("Marcela"). 1984. 186f. Dissertação (Mestrado em Farmácia) - Faculdade de Farmácia. Universidade Federal do Rio Grande do Sul. Porto Alegre. Disponível em: https:/ /www.lume.ufrgs.br/bitstream/ handle/10183/13942/000655444.pdf?sequence $=1$

SIMÕES, C. M. O. et al. Farmacognosia: da planta ao medicamento. $4^{\circ}$ edição. Porto Alegre. Editora da UFSC, 2002.

SZERWIESKI, L. L. D.; CORTEZ; D. A. G.; BENNEMANN, R. M.; SILVA, E. S. e CORTEZ, L. E. R. Uso de plantas medicinais por idosos da Atenção Primária. Rev. Eletr. Enf. [internet],2017. Disponível em: https:/ / acervodigital.ufpr.br/bitstream/ handle/1884/56461/R\%20-\%20E\%20-\%20FABIOLA\%20DA\%20ROSA\%20LUZ. pdf? sequence $=1 \&$ is Allowed $=y$

TURAK, A.; SHI, S. P.; JIANG, Y.; TU, P. F. Dimeric guaianolides from Artemisia absinthium. Phytochemistry, v. 105, p. 109-114, Sep. 2014. Disponível em: Acesso em: 10 dez. 2017. Disponível em: https:/ / agrogeoambiental.ifsuldeminas.edu.br/index. php/Agrogeoambiental/article/view/1082/pdf

VIEIRA, Fernanda Pires; REDIGUIERI, Camila Fracalossi; REDIGUIERI, Carolina Fracalossi. A Regulação de Medicamentos no Brasil. Porto Alegre: Artmed, 2013. Disponível em: https:/ / semanaacademica.org.br/system/files/artigos/a classificacao_terapeutica_como_facilitadora_do_uso_racional_de_medicamentos.pdf

VENDRUSCOLO, G. S.; RATES, S. M. K.; MENTZ, L. A. Dados químicos e farmacológicos sobre as plantas utilizadas como medicinais pela comunidade 
do bairro Ponta Grossa, Porto Alegre, Rio Grande do Sul. Revista Brasileira de Farmacognosia, v.15, n.4, p.361-372, 2005.

VENDRÚSCOLO, G.S. \& MENTZ, L.A. 2006. Levantamento etnobotânico das plantas utilizadas como medicinais por moradores do bairro Ponta Grossa, Porto Alegre, Rio Grande do Sul, Brasil. Iheringia, Ser. Bot., 61(1-2): 83-103. Disponível em: http:/ / www.sbrafh.org.br/rbfhss/public/artigos/RBFHSSV2N3\%20artigo07.pdf

WILLIAMSON, E. M. 2005. Interactions between herbal and conventional medicines 2005. Expert Opin Drug Saf 4: 355-378. Disponível em: http:/ / www.scielo.br/pdf/ rbfar/v18n1/a21v18n1.pdf

WILLIAMSON, E.; DRIVER, S.; BAXTER, K. Interações Medicamentosas de Stockley: Plantas Medicinais e Fitoterápicos. Artmed. 2012. 